\title{
No such thing as a free lunch?
}

\section{Douglas Gordon John McKechnie ${ }^{1}$, Anush Shashidhara ${ }^{1}$, Pam}

Houston ${ }^{1}$, Deborah Gill ${ }^{1}$, Paul Dilworth ${ }^{1,2}$

1. University College London Medical School, Gower Street, London, UK

2. Royal Free Hospital, Pond Street, London, UK

\section{Abstract}

\section{Background}

High-quality out-of-classroom interactions between students and teachers help to develop communities of learning. In medicine, they contribute to the professionalisation of students.

\section{Methods}

We designed a novel student-faculty lunch scheme for first year medical students at our institution. Students received a free lunch in groups of six, with a faculty member 'hosting' and paying for lunch with the cost reimbursed by the medical school. Focus groups with students were used to evaluate the impact of the intervention.

\section{Results}

Approximately half of all year 1 students signed up for the scheme $(n=153)$. Twenty faculty members hosted one or more lunches. Focus group analysis revealed that attendees felt more positively about individual faculty and the institution as a result of participation, and that it helped the process of induction and transition into medical school, but that it suffered from a lack of ongoing contact.

\section{Conclusions}

This intervention encouraged positive student-faculty interactions, albeit with a relatively small group of students. However, it did not seem to encourage longitudinal staff-student relationships, a key limitation. 


\section{Introduction}

In pursuit of the goal of maximising student learning, numerous educational institutions, including medical schools, attempt to foster the development of "learning communities"; intentional communities designed to encourage students' intellectual and professional development in a holistic and supportive way. ${ }^{(1)}$ In effective learning communities, students interact freely with each other and with faculty. Student-teacher contact has profound effects upon student learning. ${ }^{(2)}$ Positive, meaningful interactions between students and faculty in an informal, 'out-of-classroom' setting are linked to increased satisfaction with the university, personal and intellectual development, academic achievement, educational aspirations and institutional persistence. ${ }^{(2-6)}$ However, in many institutions, few out-of-classroom contacts occur between students and staff. ${ }^{(4,6)}$

Much of the Year 1 teaching at our institution is delivered in medium- or large-group format. The physical layout of the campus means that there are few natural locations where teachers and students meet, outside of programmed teaching activities. The year group is large, with over 300 students. Faculty rarely get to know students aside from those within their personal tutor groups.

This paper describes a simple intervention to promote informal interaction between first year students and faculty at our institution. Subsidized student-faculty lunch programmes have been used to encourage student engagement in the United States, 
including recently within an nursing school. ${ }^{(7)}$ To our knowledge, this is the first such programme in a British medical school.

\section{Methods}

Faculty members who were involved in year 1 teaching were approached prior to the start of the academic year and offered up to three lunch dates. Any year 1 medical student could book a place on the university's virtual learning environment. Students were unaware of the identity of the hosting faculty member when signing up. Students were assigned to groups of up to six people per lunch date. This group size was felt to be small enough to allow for meaningful interaction, but large enough to allow the entire year group to participate, given budgetary constraints. Students and faculty members could choose to meet in any local café or restaurant. Faculty hosts paid for lunch for their group, and were reimbursed for up to $f 5$ per person via the university's expense claim system.

Following completion of the lunches, two focus groups were conducted to evaluate the student reactions to the programme. Purposive sampling was employed, recruiting both attending and non-attending students in the groups to allow reasons for non-engagement to be explored. Two focus groups ( $n=9 \& n=8$ ) were conducted: one facilitated by a junior member of the teaching faculty (DGJM) and the other by a second-year medical student (AS). Recordings of the focus groups were transcribed by DGJM and AS. Thematic analysis using an inductive approach, as described by Braun \& Clarke ${ }^{(8)}$, was performed 
independently by DGJM and AS using NVivo 10 for Windows. ${ }^{(9)}$ DGJM and AS then met to compare themes and reconcile any differences in coding.

\section{Results}

Twenty faculty members participated as hosts, including the academic leadership of Year 1, non-clinical and clinical academic teaching staff, and the director of the medical school. 153 of 321 eligible students in Year 1 took part. Engagement with the lunches was highest at the start of the academic year, but student recruitment slowed significantly after the first term. The programme was significantly under-budget, with $£ 355.99$ claimed of $£ 1,875$ allocated.

Themes from the focus groups related to the perceived benefits and limitations of the scheme.

\section{Benefits}

Reducing barriers between students and staff

Participating students reported a personal connection with the hosting faculty. Several students reported that they found it easier to ask questions of their faculty host, inand outside the classroom. 
"I found it a lot easier to ask questions, when it came to [module] [...] it made it a lot easier to just approach him and ask questions" Participant 1, group 1

Participants felt they had a direct channel to senior teaching staff, allowing them to give feedback on their university experience. Students valued the opportunity to solicit advice from faculty on matters related to the course, such as study tips and the structure of assessments, but also found it useful to talk about careers and longer-term goals, and to discuss matters outside medicine.

"it gives you some perspective [...] it just gives you more of an idea that there's more to life than just medicine, really" Participant 2, group 2

Students stated that it was easy to feel anonymous in a large medical school, and that students on other degree courses tended to know their lecturers better due to smaller class sizes.

"you realise that, yeah, they [the faculty] are very learned, higher up, but they do genuinely want to help you out" Participant 4, group 2

\section{Induction and transition}

Participating students noted that, with most of the lunch dates occurring at the beginning of the academic year, the lunch scheme was important in helping them settle in at medical school. Participants learned about how the university worked, and about their 
host's role within the medical school. Many lunch groups contained a mix of students who did not know each other beforehand, and students took this opportunity to get to know other people within their year group.

"if you look back at the time we came to [medical school], that's something I do remember doing, and, yeah, I think it's part of the transition process, that really helped" Participant 5, group 1

\section{Limitations of the scheme}

One-off

Students who attended lunches rarely kept in touch with their faculty hosts. Many stated that they wished to meet again, but none from the focus groups pursued further informal contact with their hosts outside of the programme.

"there's no... continuity or whatever, because it's a one-time thing" Participant 6, group 2

\section{Awkwardness}

Perhaps unsurprisingly, non-participating students cited a fear of awkwardness as a reason not to sign up. This fear seemed to be unfounded, as students who attended reported that the lunches were enjoyable and that initial feelings of apprehension faded during the meeting. 


\section{Unclear purpose}

Non-attendees also reported uncertainty about why they should participate. Some mentioned that they did not see any benefit to their studies from attending. Others observed that whilst had engaged with other activities, such as the university's near-peer 'transition mentor' scheme, they did not think the lunches offered any additional value.

\section{Discussion}

Our student-faculty lunch scheme was generally well-received by those students who took part. Participating students valued the informal out-of-classroom interaction with teachers and felt that it reduced their feelings of anonymity within a large group. The act of buying food and drink for another can be a surprisingly powerful influence on relationships. The 'free lunch' is one of the most successful marketing tools ever devised, and has been used extensively by pharmaceutical companies to influence physician behaviour. ${ }^{(10)}$ This strategy was harnessed not only as a material incentive for students and faculty to sign up to the lunches, but also to promote feelings of goodwill towards faculty and the institution. Students generally seemed to think more positively of their faculty host; it is unclear if this also applied to the institution itself.

This intervention was limited by its one-off nature. Developing an effective learning community requires sustained student-faculty interaction. ${ }^{(1)}$ Many students in the focus groups wanted a second meeting, though none of those students canvassed had stayed in touch with their faculty host outside of the scheme. Another strategy might encourage a 
smaller number of motivated students to self-organise a series of subsidised lunch dates. Placing the onus on students to organise meetings may encourage them to take a more active role in following up with their hosts. Alternatively, combining the 'free lunch' with existing longitudinal support systems, such as a personal tutoring system, could improve student engagement with those schemes, and help build relationships with tutors. Take-up of the scheme was limited in part by fears of awkwardness and uncertainty of benefit amongst students. Those students who did attend were most likely to be engaged with, and feel positively about, faculty in the first place. Attendees felt positively about faculty interaction as part of student induction, but recruitment dropped off sharply later in the academic year. Overall, less than half of all students chose to participate, though the programme was intended to include all of the year group. For these reasons, we elected not to continue with the programme in its current form, but rather to develop a whole-year social event that involved student-faculty interaction in the Orientation and Induction week, timetabled so that all students were encouraged to attend.

\section{Conclusion}

Students value informal interactions with faculty members, and this intervention described did produce this. However, this intervention had a fairly limited appeal amongst the whole year group and was most popular during the initial induction period. As a one-off event, it did not lead to sustained student-faculty interactions over time. This type of intervention is probably most effective if targeted at a relatively small group of students, and with multiple scheduled meetings to encourage ongoing interaction. 


\section{References}

1. Ferguson KJ, Wolter EM, Yarbrough DB, Carline JD, Krupat E. Defining and describing medical learning communities: results of a national survey. Academic Medicine. 2009;84(11):1549-56.

2. Pascarella ET, Terenzini PT. How College Affects Students: A Third Decade of Research. Volume 2 edition. San Francisco: Jossey Bass; 2005. 848 p.

3. Weaver RR, Qi J. Classroom Organization and Participation: College Students' Perceptions. Journal of Higher Education. 2005 1;76(5):570.

4. Cotten SR, Wilson B. Student-faculty Interactions: Dynamics and Determinants. Higher Education 2006 1;51(4):487-519.

5. Anaya G, Cole DG. Latina/o Student Achievement: Exploring the Influence of StudentFaculty Interactions on College Grades. Journal of College Student Development. 2001;42(1):3-14.

6. Kuh GD, Hu S. The Effects of Student-Faculty Interaction In the 1990s. The Review of Higher Education. 2001 1;24(3):309-32.

7. Lewinski A, Wainwright K, Gordon H, Derouin A. Student-Faculty Lunch Program to Increase Mentoring and Facilitate Cross-Program Relationships in School of Nursing. Nurse Educator 2016;41(3):143-6.

8. Braun V, Clarke V. Using thematic analysis in psychology. Qualitative Research in Psychology. 2006 1;3(2):77-101.

9. NVivo qualitative data analysis Software. QSR International Pty Ltd.; 2014.

10. Wall LL, Brown D. The high cost of free lunch. Obstetrics \& Gynecology. 2007;110(1):169-73. 